\title{
Educação: a distância entre o dizer e o fazer
}

\section{Education: the distance between saying and doing}

\author{
José Vicente Augusto das Neves Miranda*
}

\begin{abstract}
RESUMO
Este trabalho apresenta um estudo comparado, centrado na educação e na relação entre os países desenvolvidos e em desenvolvimento, desde o período inicial da revolução industrial, principalmente na Inglaterra, até a data da sua independência. $\mathrm{O}$ artigo também relata como formas alternativas de educação, tais como a educação permanente e a educação a distância surgiram, desafiando os padrões tradicionais de educação no Estado do Paraná.

Palavras-chave: sociologia, educação permanente, países em desenvolvimento.
\end{abstract}

\begin{abstract}
In this work it is tried to resume a comparison centered on education, on the relationship between the developed and the developing countries, since the early period of the industrial revolution, mainly in England, to the date of the independence of the late. It is also repported how alternative forms of education, such as permanent education and education at distance came out defying the traditional patterns education in the southern State of Paraná, Brazil.

Key-words: sociology, permanent education, coutinuing education, developing countries.

* Professor Adjunto, Departamento de Teoria e Fundamentos da Educação da UFPR, membro do Núcleo de Educação a Distância NEAD/UFPR. Mestre em Sociologia (U.C. Louvain). E-mail:
\end{abstract} adnarima@terra.com.br 
Já que se ouve e também se lê tanto sobre a educação, tenta-se neste artigo transpirar algum resultado da diferença entre aquilo que sobre ela se disse e o que a respeito dela se fez em tempos recentes.

Retornando ao período da industrialização européia, pretende-se relembrar que as condições sociais daquelas sociedades não eram muito diferentes das que hoje vigoram nas chamadas sociedade subdesenvolvidas. Intenta-se, por isso, referir-se às etapas pelas quais foi situado o subdesenvolvimento até desembocar na devastadora realidade da globalização econômica, os países subdesenvolvidos. Pergunta-se, também, que fim levou a educação permanente? E ao tentar responder a essa questão, é possível descobrir, nas linhas que a seguir a expõem, resultados nem sempre esperados.

\section{A industrialização européia}

Aquilo que poderia dar-nos a impressão de unanimidade em aceitar o tema de a educação pertencer ao domínio da cultura, sem que este pareça desgarrado de seu meio econômico, não o era assim quando a Revolução Industrial na Europa irrompeu em certo momento de sua história.

Além disso, um feroz mercantilismo em busca de ouro nos territórios do além-mar da Europa, protegido pela mão do Estado, jogo comercial, na ânsia de disputar os favores do soberano custeador do empreendimento, parecia favorecer a concentração comercial antes sequer pensada por aqueles comerciantes que detinham apenas a experiência de trafegarem pelos canais não tão largos de seus países, como esse vasto mar onde eles estavam agora trafegando. Vejamos como essa afirmação se sustenta pelo reverso da situação que, exposta a seguir, se torna mais clara:

Os exemplos mais primitivos da empresa capitalista já existiam antes mesmo do fim da Idade Média na indústria mineira e ocasionalmente em outras indústrias. Em 1371 uma indústria têxtil em Amiens (na França), empregava 120 trabalhadores; e um tipógrafo em Nuremberg empregava o mesmo número por volta de 1450 . Nos inícios do século XVI o famoso Jack de Newburry constrói uma fábrica de tecido com mais de 200 teares, empregando 600 trabalhadores. Antes de 1660, tal empresa de grande porte, precisando da acumulação de um considerável capital, tornava-se comum, especialmente na Inglaterra. O capital necessário para as minas cresceu de uma centena de 
libras e tanto (inglesas) da época elizabetana, para muitos milhares delas, sob o reinado dos Stuarts. Fornos de explosão (blast furnaces) implicando muitos milhares de libras em capital, fizeram aparição em pleno século XVII. Em 1649 dois capitalistas despenderam seis mil libras em uma fábrica de fio de cobre. E uma cervejaria em Londres possuía um capital de dez mil libras sob Carlos I. (BROW, 1979)

Enquanto a empresa crescia a olhos vistos, como é possível deduzir da descrição acima, a mão de obra crescia também; mas as condições em que essa mão de obra crescia merece da parte do mesmo autor o seguinte comentário descritivo:

Os operários se deixaram atrair desde os seus pequenos povoados até as cidades industriais em crescimento nas quais as condições em que viviam eram deformadas, a tal ponto que se torna difícil hoje de se acreditar. Mulheres e crianças trabalhavam junto com os homens por longas horas e viviam rodeados de sujeita, promiscuidade e doenças: provenientes de um mesmo meio social e familiar, elas ficavam obrigadas a trabalhar com outros indivíduos recrutados de todo o país em fábricas situadas sem o menor respeito pelas suas necessidades fisiológicas, em lugares onde o carvão, o ferro e outros recursos tecnológicos se misturavam com os trabalhadores. Essas áreas industriais tinham um padrão de ocupação único, de tal sorte que a menor queda (de rendimentos esperados) nessas indústrias levava todos à indigência e à fome. A construção e a eficiência da moradia chegavam a um nível tão baixo que era de se arrepiar...(BROW, 1979) ${ }^{2}$.

A leitura deste quadro pretende sobretudo relembrar as condições sociais vividas pelo operariado, inglês de preferência, na época da Revolução Industrial, que eram manifestamente contrárias às condições economicamente bem sucedidas por parte dos capitães da indústria. É preciso explicitar mais do que a presente descrição, o escanteio a que fora relegada a educação em sua vertente cultural, entre as condições socialmente tão conflitivas.

1 BROWN, J.A.E. The psychogy of industry. Original. Pelican, 1979. p. 31.

2 Ibid, p. 31. 


\section{Natureza e sociedade}

O reconhecimento da vertente cultural, porém, aparece mais claramente constituído quase um século mais tarde, por meio de pressupostos aparentemente incontestáveis durante o século XIX. Poder-se-ia esboçálos resumidamente da seguinte forma. Um misto de pressuposições de ordem biológica, inovação da ciência do século XIX baseada na proposta de Darwin, inerente à seleção de espécies pelo mais apto, levava Spencer a preconizar o direito de cada um demonstrar a sua aptidão e, conseqüentemente, a uma competição sem trégua entre os seus pares. Vista por outro lado, tal pressuposição contém em seu bojo a posição dos fisiocratas econômicos, Adam Smith, Ricardo, Bentham, que estendiam a competição à liberdade dos mercados para supostamente beneficiar a humanidade. Aqueles mesmos que junto com os franceses se faziam porta-vozes da liberdade em um comércio sem fronteiras. Laisser faire, laisser passer. De um liberalismo que enaltecia a propriedade privada e os interesses de cada um. Essa posição parecia recuperar na competição o lado evolucionista do competidor. É este o movimento sobre o qual estão constituídas as Ciências Sociais no continente europeu, onde se envereda pelo materialismo da história (evolução) dos povos, uma proposta positivista da qual não escapa a posição de Marx , e da qual despontaria a proposta estrutural-funcionalista da ordem biossocial pela qual Comte se faz o grande arauto e que não deixa de se aproximar da de Durkheim.

Mas parece que é na antropologia social que essas posições ficam mais claras desde o prisma evolucionista, com que se exprime Lewis Morgan no tratamento dos produtos e dos artefactos culturais dos povos ultramarinos em relação à Europa em seu intercâmbio cientifico com esses povos, do qual nasceram muitos dos trabalhos considerados fundamentais para as Ciências Sociais, transitando de degrau em degrau conceitual até se chegar ao conceito atual. Tome-se como exemplo a Mentalidade primitiva de Levy Bruhl, ou mesmo as Formas elementares da vida religiosa de Durkheim entre os franceses e os Argonautas do Pacífico Ocidental de Malinowski, a obra de Franz Boas retirada dos estudos do índios americanos, a posição de Radcliffe-Brown Estrutura e função na sociedade primitiva, retirada dos estudos nas Ilhas de Andaman da Índia, obras que começaram a levantar pontos que enriqueceram certamente o campo da antropologia social e, por extensão, o da sociologia. Repare-se entretanto que esses autores realizaram os trabalhos dentro do campo político ao qual pertenciam os seus países: Malinowski na Nova Zelândia, 
possessão ultramariana britânica; Radcliffe-Brown na Índia, Boas nos Estados Unidos, Levy Bruhl nas colônias francesas da África, levando um certo culturalismo colonizante por detrás das relações comerciais e políticas que detinham soberanamente nesses países. Tendo ficado no fogo cruzado das duas guerras, esse culturalismo colonizante acabou desembocando na independência política da Índia em 15 de agosto de 1947, após a luta política liderada pelo Mahatma Gandhi.

A partir desse momento o tablado de dominó armado pelas superpotências da época começou a desmoronar, mas é preciso dizer também que esse momento é crucial, destinado a ser realçado como momento da educação no “Terceiro Mundo". É importante recuperar tal expressão, pois ela denotava o momento político vivido pelas nações colonizadas em fase de descolonização: "Terceiro Mundo" exibia a constituição política de sobretudo três blocos econômicos, sendo o primeiro constituído pelas antigas metrópoles com evidentes laços econômicos com as suas ex-colônias e conhecido como "Primeiro Mundo", ao que se seguia o bloco constituído pela União Soviética e por um cinturão de países próximos ao território da própria União Soviética e imaginado como "Segundo Mundo", frente ao grande contingente dos países de independência progressiva na década de 50. Para enfeitar o despudor da exploração de comércio desigual tinha de se achar um outro nome numericamente menos hierarquizante, o que aconteceu com a expressão "países subdesenvolvidos" até a expressão se acomodar um pouco mais elegante em "países em desenvolvimento".

Pela lógica que constituiu os blocos econômicos em políticos, os países da América Latina acabaram sendo lotados entre "os países em desenvolvimento", ainda que a independência desses países tivesse sido alcançada antes da década de 50 do século XX.

Na sumaríssima alusão ao histórico das condições constitutivas dos blocos econômicos, estas podem, entretanto, ser retomadas do ponto de vista daquelas descritas por Freund ${ }^{3}$ em um quadro conceitual da sociologia da dominação de Max Weber. Esse quadro conceitual pode ser explicado a partir da sociologia política de Weber.

É possível recorrer, do ponto de vista metodológico, à posição adotada por GLEISER, sobre o fato de que "as teorias são construídas com base em certas suposições que devem ser passíveis de confirmação ou refutação experimental. São os experimentos que têm a última palavra, não as teorias, por

3 FREUnd, J.A. Sociologia de Max Weber, Rio de Janeiro: Forense, 1987. 
mais elegantes que elas sejam"4. Com efeito, referindo-se na realidade à política alemã do início do século XX, Weber parte de certas premissas tais como a liderança política, a consolidação institucional, a estabilização territorial e o caráter nacional.

Curiosamente, tais considerações, segundo Weber, poderiam ser a opção de uma Alemanha que ele supunha senhorial, mas não o é. O tipo ideal de referência política de Weber parece ser antes a Inglaterra, dotada de todas as condições acima mencionadas e a tal ponto que é pertinente citar textualmente a pergunta feita pelo próprio autor a propósito daquele país: "Será este um Estado-vigia-noturno que conseguiu incorporar a si mesmo a despeito da sua diminuta população as melhores partes de todos os continentes?"

Pode-se, portanto, nesse histórico, localizar na linha do quadro conceitual da dominação, outros países além da Inglaterra vistos como superpotências, tais como a França, Portugal, Holanda, Bélgica e Espanha, capazes de terem exercido o domínio sobre outras nações. Essas super-potências detinham domínio sobre territórios situados em regiões ultramarinas em relação a seu próprio território e podem ser denominadas metrópoles dos países que são chamados de Terceiro Mundo. Porém, a partir de 1947, ano em que a Índia obteve a independência, o estatuto de metrópoles das superpotências passa a ser o de "antiga metrópole", trazendo como consequiência novas relações políticas entre esses países e suas ex-metrópoles. As relações econômicas, ao contrário, permaneceram amarradas ao conceito de dominação, no sentido de que "existia relação assimétrica entre o centro industrializado e a periferia fornecedora de matérias-primas e que o progresso técnico propagava-se muito lentamente do primeiro em direção ao segundo" 5

Pode-se também conceber nas relações de dominação certos problemas decorrentes das relações no desenvolvimento econômico, das quais surgem no horizonte do desenvolvimento momentos altos e baixos, como é aquele surgido na década de 60. Rostow consignou tal momento alto sob o nome de take-off em sua obra As etapas do crescimento econômico ${ }^{6}$, sem que entretanto os países neo-independentes pudessem subtrair-se à lógica econômica 2000.

4 GLeISER, M. Os fantasmagóricos neutrinos, Caderno Mais, Folha S. Paulo, 07 out

O resumo de Gleiser parece oportuno sobre a construção e confirmação de teorias. A nosso ver "os experimentos" poderiam ser substituídos por fatos largamente confirmados no decurso da história a despeito da interpretação pela qual se apresenta esse fato histórico.

5 Ricupero, R. A globalização de Raul Prebisch, Folha de S. Paulo, 02 set 2000.

6 Rostow, W. W. Les étapes de la croissance economique, Paris: Editions de Minuit, 1970. 
subjacente às relações de dominação e "decolar", como era a aspiração dos economistas.

Seria uma temeridade dizer que as relações de dominação eram exercidas apenas do exterior das novas independências ou nos países da América Latina. Uma plêiade de autores latino-americanos tratou dessas relações e delas surgiu com diferentes enfoques o tratamento da relação de dependência, definida assim por um brasileiro: "situação em que a economia de determinados países fica condicionada pelo desenvolvimento e pela expansão de outra economia, à qual fica submetida a primeira" (Teotônio dos SANTOS) $)^{7}$.

Em resumo, esses autores dizem que como conseqüência da relação de dependência na fase colonizadora, a educação não teve um desenvolvimento cultural endógeno, enquanto que, passada essa fase, o modelo cultural de universidade instaurado na América Latina, e sobretudo no Brasil, foi o da universidade napoleônica para a formação da elite dirigente e da classe burguesa apenas incipiente, porém norteada pelo positivismo como fundamento científico e o liberalismo econômico e político como pensamento político ${ }^{8}$.

A implantação do modelo francês proveniente da hegemonia impositiva exercida naquele período pela França, da referência originada das elites internas, fez com que em momento algum as universidades exercessem uma função crítica ao sistema vigente, aceitando passivamente o ou os modelos impostos.

Ora, nessa etapa era principalmente a educação que era vista ter a capacidade de reverter esse processo de dependência, pela autonomia com que a educação e sobretudo a escola se apresentam nos sistemas culturais. Neste caso a Universidade que optasse ou chegasse a optar por uma autonomia que como se vê é relativa, poderia cumprir um papel político, tanto de denúncia das injustiças sociais numa sociedade de classes quanto de minimização da dependência cultural com o exterior ${ }^{9}$.

A lógica do poder dominante, entretanto, achou uma outra saída após duas ou três décadas do fim da Segunda Guerra, com o movimento sindical havendo alcançado algumas de suas metas, na substituição da mão de obra operária pelo crescente emprego das tecnologias modelado pelo amplo uso efetuado nos E.U. e que chegam ao seu ponto mais alto com a expressiva extensão do deslanchamento da tecnologia da informática na década de 90.

7 Garcia, P. B. Educação, modernização ou dependência, Rio de Janeiro: Francisco Alves, 1977.

8 Barros, R. S. M. A ilustração brasileira e a idéia de universidade. São Paulo: ConvívioEdusp, 1986. p. 363.

9 GARCIA, P. B. op. cit., p. 60. 
No mundo inteiro a substituição da mão de obra tomou uma forma cada vez mais avassaladora, esvaziando a voz dos líderes sindicais e a sua máquina administrativa, em busca de "qualificação" por força do "enxugamento" que todas empresas de pequeno ou de grande porte estavam efetuando. Um movimento com característica de políticas neoliberalistas que começara a circular nos países desenvolvidos na década de 80 como impacto político de quase uma década do governo conservador de Margareth Thatcher e do governo republicano de Ronald Reagan nos E.U. estava chegando aos países do "Terceiro Mundo". No Brasil na década de 90 esse movimento vinha revestido de uma aura globalizante parecendo seguir a regra infantil do jogo frente aos brinquedos: "os meus brinquedos são meus e os teus brinquedos são nossos". Nesse movimento neoliberal liderado pelos países ditos desenvolvidos as mesmas ex-metrópoles do Estado Vigia-Noturno ou de economias centrais, em reuniões periódicas deixavam entrever leis de comércio favoráveis a eles próprios, criando mais uma vez o desequilíbrio econômico dos países chamados subdesenvolvidos ou da periferia. Pelo emprego de tecnologias varias vezes acessíveis aos assalariados do "Terceiro Mundo", repetia-se a natureza do fenômeno político-econômico em uma nova fase: na segunda metade do século XIX, mascarando uma dominação colonialista de tipo imperialista, reproduzida durante a fase da descolonização um século depois, voltava-se agora não somente à reprodução, mas ao recrudescimento da forma capitalista primitiva durante a década informatizada de 90 . Submetidos à lógica da dominação, tais processos permitem se perguntar: "para que fabricar nas economias centrais uma peça que pode ser fabricada nos países periféricos por um custo infinitamente menor?" Como indicador comprobativo dessas afirmações basta comparar a situação descrita na indústria inglesa no início deste trabalho com as páginas dos jornais brasileiros e de outros países do Terceiro Mundo. E é triste verificar que não se trata de uma crônica humorística de Millor Fernandes ${ }^{10}$.

\section{A urgência de novas pistas}

Esta situação caótica, seja ela vista como um resultado de uma política de dominação ou de um capitalismo fagocitário, não passou despercebi- 
da das instâncias internacionais, embora compostas por delegações dos países do Primeiro Mundo. E é assim que tem de ser vistos os esforços da Unesco no sentido de ir ao encontro dos males causados por tal situação e é assim que a Unesco reuniu, desde a década de 80, vários seminários regionais, um dos quais foi realizado em Brasília em 1988, a Conferência Mundial sobre o Ensino Superior, com o intuito de "criar uma nova dinâmica e recomeçar um processo que se tornará de fato um processo permanente de reflexão e ação, para melhorar a qualidade e relevância da educação superior, tornando-a mais eficiente na construção de uma sociedade mais justa"11

Após rever o caso de certos países do continente africano onde as oportunidades de alcançar o ensino superior são $17 \%$ menores do que os seus equivalentes dos países industrializados (no caso dos países em desenvolvimento resulta quatro vezes menores do que esses), os países membros da OCDE propuseram desde 1983 a mudança do paradigma para a educação do terceiro grau que propõe a participação "de todos os que tiverem completado em uma outra forma de educação terciária em qualquer ponto da vida de alguém e não necessariamente na prolongação imediata da educação secundária" ${ }^{2}$. Redefine, pois, a educação terciária como acesso não apenas a uma faculdade, mas a um meio de vida, não apenas para poucos mas para todos:

"Na proposta desse novo paradigma, a educação superior ou terciária seria a meta a ser alcançada por 60,80 ou até $100 \%$ dos que completassem os seus estudos secundários" ${ }^{13}$.

"Sem outro critério de acesso que não fosse o mérito do candidato, que junto com a sua habilidade e motivação deveriam constituir a única base de acesso à educação, deveriam constituir a única base de acesso à educação superior, com nenhuma discriminação sendo permitida para restringir o acesso. Neste sentido a participação de mulheres onde elas estejam sub-representadas é proposta como objetivo a ser alcançado"14.

Objetivos desse porte podem ser alcançados, segundo as diferentes Conferências Regionais, sendo o sistema educacional tratado como um todo, no qual a educação superior seja vista como sistema público. As novas tecnologias, neste caso, deveriam ser postas a serviço do processo peda-

11 A Unesco e o Futuro do Ensino Superior, Curitiba: UFPR, 1998.

12 Ibid.

13 Ibid.

14 MARTins, O. B. A educação superior à distância e a democratização do saber. Petrópolis: Vozes, 1991. 
gógico, assim como do progresso da pesquisa, servindo para uma gestão mais eficiente dos sistemas de educação superior baseados no acesso de todos a essa educação permanente.

\section{Educação permanente no Paraná}

O movimento da mentalidade que punha a educação como uma das condições de superação do desenvolvimento nos anos 70, teve, como não poderia deixar de ser, grande repercussão no meio acadêmico brasileiro. A educação, neste caso, representava a grande esperança que haveria de "resgatar"(era essa a palavra-chave repetida em todos os meios qualquer que fosse o tema de discussão!!!) e retirar o país do subdesenvolvimento em que se encontrava atolado. Na Universidade Federal do Paraná essa repercussão tem lugar sobretudo na criação de uma área de concentração com o nome de "Recursos Humanos e Educação Permanente" em 1983 no Programa de Pós-Graduação em Educação, o que proporcionou ampliar o terreno de discussão para um sem-número de áreas de ensino mediante os trabalhos de no mínimo 79 dissertações orientadas pelos professores do Programa.

A discussão amadurecera como educação permanente, a ser levada ao conhecimento dos acadêmicos e dos professores como uma forma de saída para a situação da fase de subdesenvolvimento. Essa discussão pode ser condensada de uma maneira abrangente em duas obras de professoras que a abriam após a estadia em centros universitários europeus. A primeira delas $A$ educação superior à distância e a democratização do saber, a qual se propunha difundir os diferentes meios pelos quais o Movimento Nacional de Formação do Educador continuou mobilizando todos os profissionais do ensino formal, no sentido de fazer avançar o processo de democratização do saber em favor das classes menos favorecidas perante a retroação progressiva no processo da democratização do ensino. Consciente de que "instituições tais como a Universidade de Brasília e outros órgãos de nível estatal dispunham de projetos e experiências empenhados na educação superior aberta à distância", a autora Onilza Borges MARTINS diz que "vários outros fatores tais como a carência de professores competentes para o exercício do magistério no ensino fundamental e médio ( $1 .^{\circ}$ e $2 .^{\circ}$ graus), a atualização desses 
professores, a dificuldade de cursos presenciais acenam à Universidade, instituição formal com acesso aos bens culturais, uma ação cultural a qual sem privilegiar uma clientela de elite seja exercida em sentido amplo com vistas à transformação social de toda a comunidade. Desta maneira, o acesso ao ensino a distância apresenta-se como uma situação concreta para toda a situação brasileira que independente de sexo, raça ou classe, por razões sociais e econômicas não teve oportunidade de se apropriar do conhecimento e das informações necessárias ao processo de progressão humana e social" 15 .

Alguns condicionantes que fragilizam a ação planejadora e administrativa da educação, dos quais resulta a má qualidade da educação, oferecem traços de uma moldura de dilemas que inviabilizam a ação educacional. Um primeiro pertence ao domínio da decisão política maior, cuja racionalidade econômica exclui sistematicamente do desenvolvimento a educação e a cultura. Sinal de evidência desse tipo de dilema é a exaltação da chegada do Brasil ao lugar de oitava economia do mundo, nas circunstâncias em que a educação e cultura foram descritas. Descompromisso acentuado, portanto, por parte da universidade de avaliações críticas das políticas educacionais, as quais, envolvidas com o progresso dito tecnológico, absorvem recursos financeiros para esta finalidade sem entretanto se priorizar um contato maior com o ensino de $1 .^{\circ}$ e $2 .^{\circ}$ graus. O educando menos favorecido fica portanto distante dos conteúdos curriculares que o tornariam um cidadão participante e consciente. Isso leva a autora a criar uma hipótese de trabalho de que "as universidades brasileiras necessitam urgentemente de atender as demandas sociais das classes menos favorecidas e, conseqüentemente, reverter o processo pelo qual no Brasil o progresso científico e tecnológico possa ser fruto da educação e planejamento sistemático, sem que a educação seja privilégio das classes da elite reproduzindo as desigualdades das estruturas sociais existentes". Em face desta hipótese, a autora se empenha em aspirar porque "o ensino superior aberto e à distância devido à sua flexibilidade se apresenta como uma alternativa valiosa de democratização para suprir em parte a demanda da atualização dos jovens e adultos de diferentes categorias profissionais, permitindo que muitos indivíduos participem da educação coletivamente"16 .

15 MARTins, O. B. A educação superior à distância e a democratização do saber, Petrópolis: Vozes, 1991.

16 Ao autor foi pedido para retirar da circulação de leituras um texto de G. LABARCA Educación, ideología y superestrutura. Explicado, ao saberem que o tema "superestrutura" pertencia à epistemologia do pensamento marxista, foi tratado de "comunista", o que em 1979 podia ser considerado como se fosse um atentado à ordem social e política aos cuidados da polícia DOPS. 
Mas os anos da década de 80 , sobretudo na segunda metade, foram a época de transição da ditadura militar à democracia, culminando com a eleição do Sr. Tancredo Neves. A partir de 1985 entrou-se para a fase de consolidação do regime democrático pela criação, em fevereiro de 1986, de uma nova moeda simbolicamente demolidora da inflação a que o país tinha chegado, e pelas eleições para a Assembléia Constituinte. Nesse período, as falas dos políticos queriam diferenciar-se da época da ditadura, enfraquecida ultimamente pelo movimento operário do ABC paulista liderado pelo Sr. Luís Inácio da Silva, o popular Lula. A academia se caracterizava pelo pensamento marxista, enaltecido por todos os partidos banidos durante o regime militar e especialmente aquele nascido das lutas do ABC paulista como o Partido dos Trabalhadores. A influência enorme do pensamento marxista excluía dos meios acadêmicos qualquer outro que não fosse esse, legitimando uma oposição com outra forma de pensar, especialmente o positivismo atribuído ao stablishment militar e político da ditadura militar, embora não se desdenhasse dentro dele a infra-estrutura econômica e a superestrutura político-cultural da qual muitos sequer haviam ouvido falar ${ }^{17}$.

Perante o panorama político do país, a obra de Onilza Borges Martins, embora trazendo uma criativa opção para a academia, teve uma repercussão abaixo da esperada na Universidade Federal do Paraná. Não se é possível afirmar nem negar que talvez fosse porque essa proposta não se encaixava dentro do pensamento marxista considerado, naquele momento, politicamente correto, sem que o "mal-estar" causado por esta publicação se dissipasse senão alguns anos mais tarde quando a autora se retirou da presença ativa na Universidade pela aposentadoria. Qualquer que fosse o motivo do fato exposto, em certo dia ensolarado não tão frequiente em Curitiba, foram achados 40 exemplares retirados sorrateiramente de circulação e escondidos em arcano que não pode ser chamado seriamente de "baú de felicidade". O conteúdo da discussão levantado pela obra pode ter sido rejeitado, então, mas permanece atual.

A outra obra, de que houve noticia acima, é uma transposição criativa de um dos setores da vida social menos esperado em matéria de"educação permanente", que é o político e expresso em seu título: Educação permanente: da reunificação alemã a reflexões e práticas no Brasil. A discussão que tinha lugar no Programa de Pós-Graduação em Educação na UFPR permitia a

17 KNECHTEL, M. R. Educação permanente: da reunificação alemã a reflexões e práticas no Brasil, Curitiba: Editora UFPR, 1994. 
vinda de autores como o francês Bertrand Schwartz e o suíço Pierre Furter aportarem os seus pontos de vista ao conceitual da educação permanente, seja em termos de educação pós-universitária, educação de adultos, e educação a distância. A autora, Maria do Rosário Knechtel, com essa obra acrescentava ao debate um domínio ainda mais vasto, qual seja, o político. Um dos primeiros pontos a ser realçado é o fato de a Universidade nunca se ter fechado para os problemas da comunidade conquanto fosse muitas vezes tratada de retrógrada e alienada, pois a autora visualiza o problema da reunificação alemã como todo cientista social visualiza melhor os problemas que estão fora do meio onde vive e trabalha. Contribui, com essa colocação do problema, metodologicamente em favor das dificuldades de abordagem do objeto da sociologia pelo pesquisador. A seguir a autora diz que a educação permanente é entendida "num conceito mais amplo como a busca de cidadania, da liberdade e do respeito mútuo entre a população adulta de uma sociedade moderna e que pode levar o homem a melhor situar-se na sociedade atual, especialmente no contexto em que vive e convive e assim alcança o exercício pleno de cidadania" 18

"A educação permanente foi evidenciada como meio auxiliar na mediação de mudanças sociais e políticas da unificação alemã, ora com avanços ora com recuos" e em relação com a reflexão dos educadores brasileiros a autora pretende oferecer "observações e reflexões realizadas em outros países 'e' constituem sempre uma oportunidade importante e interessante, não tanto para efetuar comparações, mas para transmitir conhecimento do que está acontecendo e se desenvolvendo naqueles países", fornecendo uma contribuição ao seu pensamento, sua crítica e sua ação ${ }^{19}$. Surge neste trecho da obra, uma vez mais, o esforço de clarear o método sociológico adotado pela autora para tornar a educação permanente objeto de sociologia de educação. Já Barbara Freitag, que prefacia o livro e é reconhecida autora do meio acadêmico brasileiro pela sua obra, amplia o conceito de educação permanente para três de seus registros, o econômico, o político ideológico e o técnico profissional, cada um dos quais demanda condições diferentes na concepção do exercício da cidadania ou segundo me parece, poder-se-ia traduzir a opinião dessa autora em termos propostos por Berger-Luckmann ${ }^{20}$ na aquisição da socialização secundária que precisa ser conquistada permanentemente pela sociedade.

18 KNECHTEL, M. R. Educação permanente: da reunificação alemã a reflexões e práticas no Brasil, Curitiba: Editora UFPR, 1994.

19 Ibid.

20 Ibid. 
A obra foi lançada em 1993 e o conceito de educação permanente que nela dá suporte à reunificação alemã parecia nesse momento tomar a dianteira do projeto de possíveis mudanças que poderiam ocorrer na aproximação de quatro países latino-americanos politicamente diferentes que estavam constituindo e firmando uma aliança conhecida como Mercosul. Como se dizia na imprensa local "assistimos também no Brasil a uma conturbada marcha em direção a um mercado comunitário, o Mercosul, sem exatamente se saber qual a feição com que os mercados regionais dos países componentes ficarão" 21 .

A autora visava portanto não só a educação permanente com tal, mas preocupava-se também com a educação permanente como construtora de projetos nacionais, em vias da constituição de um mercado econômico, para cuja discussão propunha uma base sociológica de caráter teórico. Parecia com isso remeter-nos à constituição da civilização européia por meio do trabalho realizado na medievalidade européia pelo monacato ao qual a história da Europa não deixa de ser sensível.

A partir dessa época, o tema da educação permanente na Universidade Federal do Paraná pareceu emigrar para outros temas tais como a educação de jovens e adultos constituída doravante em disciplina de Graduação.

A essa altura remete-se o leitor ao movimento internacional acima descrito organizado pelas instancias internacionais das Nações Unidas ao qual a Universidade não podia ficar indiferente. É no bojo desse movimento que se desenvolve a educação a distancia. Os precedentes aos quais nos referimos ao longo deste trabalho podem se constituir em elementos que compõem o quadro que deu origem ao Núcleo da Educação a Distancia na Universidade Federal do Paraná.

Parece, portanto, cabível concluir que a educação, como qualquer outro tema que seja tomado como objeto nas Ciências Sociais possa ter passado por circunstâncias como as que foram aqui descritas no decorrer de seu desenvolvimento bem como ter sofrido embates parecidos com aqueles que aconteceram anteriormente em países em que acontecimentos e circunstancias viram a luz em passado prévio ao aqui considerado. O que entretanto chama a atenção é o que se substancia na posição teórica aqui adotada, a dominação, e que permite remeter-se ao fato de os países em desenvolvimento parecerem girar sobre o seu próprio eixo sem que se possa detectar neles a semente de mudança das condições sociais daqueles em que se

21 KNeCHTEL, M. R. Educação permanente: da reunificação alemã a reflexões e práticas no Brasil, Curitiba: Editora UFPR, 1994. 
encontravam à véspera de sua independência. Seria também falso, confesse-se, generalizar.

No Brasil, no período do após a década de 50, até mesmo acontecimentos auspiciosos tais como a abertura democrática, o fim da censura e das condições coercitivas como exigências de uma ditadura militar, parecem não permitir que a mudança social tão desejada causasse com a expectativa por ela criada. Pelo contrário, vários indicadores sociais publicados pela imprensa demonstraram a manutenção inalterada da renda das populações, se esta fosse considerada como um dos indicadores da mudança desejada.

A educação a distância, neste sentido, pode vir a ser um dos importantes caminhos para que a desigualdade social possa enfim vencer a distância que vai entre o dizer e o fazer, amenizando ao menos os critérios que a tornam aparentemente algo inextirpável.

\section{REFERÊNCIAS}

FREUND, J. A. Sociologia de Max Weber, Rio de Janeiro: Forense, 4. ed., 1987.

GLEISER, M. Os fantasmagóricos neutrinos, Caderno Mais, Folha S. Paulo, 07 out. 2000.

MARTINS, O. B. A educação superior à distância e a democratização do saber, Petrópolis: Vozes, 1991.

RICUPERO, R. A globalização de Raul Prebisch, Folha S. Paulo, 02 set. 2000.

ROSTOW, W. W. Les étapes de la croissance economique, Paris: Editions de Minuit, 1970.

Texto recebido em 20 jan. 2003

Texto aprovado em 20 mar. 2003 


\section{ANEXO}

Discurso proferido pelo Sr. Governador do Estado do Paraná, Dr. Bento Munhoz da Rocha Neto, encerrando a sessão de instalação da 11. ${ }^{a}$ Conferência Nacional de Educação, em 7 de janeiro de 1954, às 21 horas, no Salão Nobre do Colégio Estadual do Paraná, na cidade de

Curitiba.

O SR. BENTO MUNHO DA ROCHA NETO, Governador do Estado Ao encerrar esta sessão de instalação da 11. ${ }^{a}$ Conferência Nacional de Educação, quero, como Governador do Estado do Paraná, afirmar a simpatia, e mais do que simpatia, o carinho com que testemunho esta reunião.

Houve ainda uma coincidência tão bem referida pelo meu nobre amigo Prado Kelly; na 1. ${ }^{a}$ Conferência Nacional de Educação, aqui realizada em dezembro de 1927, quando dirigia o Paraná Caetano Munhoz da Rocha, que teve a intuição, aquela intuição quase divinatória de como o Paraná se estava formando e preparando, para ser hoje o grande cadinho nacional e como o Paraná ia depender do professor, do educador.

A Prado Kelly, que tanto me sensibilizou com as suas generosas palavras, a homenagem do Governo do Paraná a essa Associação que ele, tão altamente, preside.

O Governador do Paraná vê com satisfação o seu amigo, colega de 5 anos de Câmara. Rever Prado Kelly é um prazer. Ele é um dos parlamentares mais completos do Brasil. Para ser parlamentar é preciso possuir uma série de qualidades. É preciso possuir cultura; cultura jurídica e cultura geral. Mas, não basta isso. É preciso ter aquela plasticidade, aquela mobilidade espiritual que dê, de fato, razão ao parlamentar, ainda quando ele não a possua. Prado Kelly tem, como parlamentar, o velho e consagrado estilo britânico. $\mathrm{Na}$ exposição perfeita, em que eu, uma vez na Câmara, ouvindo-lhe a defesa de determinado projeto de lei, disse-lhe que ele era um dos parlamentares cuja palavra podia não fazer mudar de voto, mas mudar de opinião. Penso que essa é a consagração máxima a um parlamentar. É difícil que os companheiros mudem de voto, mas mudam de opinião. O voto, que é um segundo ato da atitude parlamentar, vai mais além da opinião, porque é, quase sempre, questão de compromisso político-partidário e, muitas vezes, contraria a opinião.

Vejo, com satisfação, este Congresso Nacional de Educação, porque sou, 
como repetidas vezes tenho afirmado, por vocação, um professor. Reconheço e proclamo o papel fundamental que a educação e, conseqüentemente, o professor, representam nas sociedades modernas. Sobretudo, numa região que, fisicamente, social e economicamente, e ainda mais sob o ponto de vista do seu riquíssimo elemento humano, se define com as dimensões paranaenses. Temos aqui a noção exata das repercussões extraordinárias da educação. Não falarei nos milagres da educação. Seria preciso distinguir Educação sob o prisma, sob o aspecto, sob a accepção sociológica que é, acima de tudo, uma transmissão de cultura e educação sob o ponto de vista pedagógico, uma transmissão sistematizada de cultura.

Tudo é educação sob o ponto de vista cultural, sociológico, mas não é educação sob o ponto de vista pedagógico, sob o ponto de vista da sistemática.

Nenhum professor pega a criança no marco zero. Toma o educando com todas as suas heranças, com todas as suas taras, com todos os seus prejuízos, com todas as suas qualidades e com todos os seus defeitos. Temos, no Paraná, talvez melhor do que em qualquer outra região brasileira, a noção exata de quanto vale a educação, de tudo quanto se pode esperar da educação. É pela educação que nós, paranaense, incorporamos, em poucas dezenas de anos, milhares de brasileiros à cultura brasileira. Brasileiros filhos de estrangeiros, filhos de alemães, filhos de poloneses, de ucranianos, - já não falo dos síriolibaneses e dos italianos, que pelas suas afinidades culturais, na segunda geração, culturalmente, brasileiros, mas, daquelas culturas que, originariamente, mais se distanciam do nosso modo de ser. Nós, paranaenses, incorporamos descendentes dessas etnias, dessas culturas, não apenas à nacionalidade brasileira, - não queremos cidadãos brasileiros que tenham direitos de cidadania garantidos pela Constituição Federal, mas brasileiros pelo espírito, pela cultura, pela formação, pela ração, pelo modo de ser, pelo modo de reagir diante da vida e do mundo. Este é o mérito com que o Paraná se apresenta, ao comemorar o seu centenário, diante do Brasil.

É o incorporador, formador do brasileiro. E temos aqui, mais do que nunca, a consciência do valor do Estado na máquina educativa. É o Estado que uniformizando os processos educativos, faz com que os brasileiros tradicionais do Paraná e os brasileiros que eram originariamente brasileiros, apenas porque aqui nasceram, venham a possuir, de início, os mesmos sistemas de idéia na uniformização da máquina da sistemática educacional. Daí a importância do Estado. Mas, esta nossa experiência paranaense que tão bons resultados tem dado ao Paraná ao Brasil, serve, também, para corrigir os exageros do Estado no funcionamento da sua máquina educacional, sendo mais 
do que nunca necessário que o Estado venha agir no campo educativo, como em todos os outros campos em todas as atividades humanas, democraticamente. E o segredo do Estado democrático está nisso: uniformizar a educação. Mas uniformizar sem constranger, fugindo daquela fabricação totalitária de crianças em série, de homens que não são mais seres humanos porque perderam do ser humano aquilo que lhe é característico, a personalidade, a diferenciação de todo ser diante de si, de todos os seres diante da vida, diante do mundo.

Em função do Estado Democrático é que se distingue profundamente das funções do Estado Totalitário, que, mais do que qualquer outro, percebeu como é fundamental para a organização social moldar a criança.

O jesuíta que foi mestre, o jesuíta cuja história na América se confunde, durante séculos, com a própria história da nacionalidade, teve aquela admirável intuição: trazia instruções da metrópole para que respeitasse a crendice e a idolatria dos velhos índios e ficassem apenas com as crianças e amoldassem, cristianizando, o jovem índio. Sabedoria pedagógica de 400 anos, sabedoria pedagógica que o Estado totalitário perverteu, fabricando em série homens que não conhecem outro mundo, senão aquele mundo que o próprio Estado consente que seja conhecido.

Essa função do Estado Democrático, no campo da educação, sobe de importância quando, desgraçadamente, sob o ponto de vista cultural, sociológico e histórico, o momento que vivemos é o fim do Renascimento. O nosso mundo perdeu o amor da liberdade. Tem preferido à liberdade a eficiência. Tem preferido os Estados eficientes, que realizam materialmente, aos Estados Democráticos, em que o homem tem sagrado o direito de afirmar as suas preferências políticas, e dizer que não aceita, necessariamente, o que vem do Governo, por ser do Governo.

O mundo moderno perdeu a fascinação pela liberdade e é muito comum, mesmo no nosso meio, que tem raízes democráticas tão profundamente marcadas na nossa tradição - ainda hoje ouvi - a preferência pelas ditaduras disciplinadoras, que constroem grandes edifícios, grandes escolas, grandes hospitais e estradas de primeira classe.

É o estado de espírito que ao professor compete extinguir. Não há prosperidade econômica, não há prosperidade material que compense o sacrifício da liberdade. Não há pseudo-progresso, porque o progresso só se pode definir pelas suas dimensões espirituais. Não há pseudo-progresso que se possa justificar à custa da liberdade, essa extensão de nossa própria personalidade. Mas, é preciso, também, convir que a atitude do Estado na educação não pode ser mais a atitude do Estado Liberal. O Estado desconhecia os problemas da 
origem e da finalidade do homem e da vida humana. Os grandes democratas norte-americanos desde Lincoln a Roosevelt e Eisenhower, reconhecem a origem religiosa da liberdade. Se não se der ao homem a sua característica religiosa, de espiritualidade, não sei com que argumentos poderão combater os pendores naturais.

O Estado Totalitário coloca o interesse do Estado acima do interesse da pessoa humana. Se o homem não é um ser espiritual, feito para a eternidade, com um destino que ele vai conquistar pelos seus méritos espirituais, que vai conquistar, qualquer que seja a sua raça, a sua cultura, ou a sua nacionalidade, não sei com que argumentos seguros se poderá combater o Estado que se coloca acima da pessoa, que serve da pessoa e dos indivíduos.

Quando o mundo não tinha ainda caminhado como caminhou nestes últimos tempos, quando ainda as opções não eram agudas e angustiantes, como o são no dia de hoje, era possível ao Estado dar de ombros, diante das indagações do homem, em face dos problemas fundamentais da vida. Hoje, não. As definições estão muito apertadas e os erros do Renascimento chegaram a todos os seus extremos. Por isso, mais do que nunca ao Estado compete a sua verdadeira função, função democrática, mas função também humana, que concilie o que é nacional com o que é humana. Prado Kelly se referiu, e se referiu muito bem, à caracterização regional do Paraná. O Brasil é uma Federação. O Brasil é um corpo imenso e, como tal, possui caracterizações regionais que devem ser mantidas, o Brasil é um mundo na sua variedade.

Daí, como o Estado não deve criar conflitos entre o que é nacional e o que é humano, não deve também criar conflitos entre o que é nacional e o que é regional, o que é do pequeno setor da Pátria grande. Esta reunião que congrega em Curitiba os grandes educadores nacionais, tem um campo vastíssimo diante de si, principalmente com a Carta das Nações Unidas, com essa inovação do Direito Moderno, essa inovação que vem restringir certos conceitos, como aquele da cidadania, a que Prado Kelly se referiu. Conceitos que muitas vezes nos dão a idéia exata daquelas idéias que enlouqueceram, a que Chesterton se referia, idéias que se querem realizar, mas que se querem realizar inconscientemente. Aos educadores, mais do que aos governadores, cabe o futuro do Brasil. A unidade alemã, muito antes de Bismark, em 1870, foi feita, foi iniciada depois da batalha de Viena por Suss. Suss não falava aos prussianos, falava ao povo alemão. Foi a preparação, uma preparação psicológica, social, política, nacional que desabrochou então, depois da batalha de Viena.

A função dos educadores é muito mais profunda do que a função dos governantes. É claro que os benefícios ou os malefícios dos governantes po- 
dem perdurar por várias gerações, mas na mediocridade do mundo moderno os governos fazem sentir os seus atos pouco além do seu próprio período. O Educador, não! O Educador marca, tem a paternidade espiritual. Daí a responsabilidade do educador. Não apenas do homem que instrui, mas do homem que educa. Instruir apenas é um pedaço diminuto, quase infinitesimal da educação. Educar é formar, é plasmar o homem de amanhã.

O Governador do Paraná está, neste instante, honrado com a presidência desta Conferência, homenageando o educador brasileiro. E vem afirmar, com a responsabilidade do seu cargo, que confia no Brasil porque confia no educador brasileiro. (Palmas prolongadas)

O documento aqui publicado, que é o discurso do ex-Governador do Paraná Bento Munhoz da Rocha Neto, foi cedido pela Prof. Pórcia Guimarães Alves, do Departamento de Teoria e Fundamentos da Educação, de seu arquivo pessoal, pelo que a Coordenação desta edição agradece. 